\title{
Identification of gene polymorphisms of human DNA topoisomerase I in the National Cancer Institute panel of human
} tumour cell lines

\author{
F Moisan ${ }^{1,2}$, M Longy $^{3}$, J Robert $^{*, 1,2}$ and V Le Morvan ${ }^{1,2}$ \\ 'Laboratoire de Pharmacologie des Agents Anticancéreux, Institut Bergonié, 229 Cours de l'Argonne, 33076, Bordeaux-cedex, France; ${ }^{2}$ Université Victor \\ Segalen Bordeaux 2, 146 rue Léo-Saignat, 33076, Bordeaux-cedex. France; 'Laboratoire de Génétique, Institut Bergonié, 229 Cours de l'Argonne, \\ 33076, Bordeaux-cedex, France
}

Topoisomerase I (Top I), a nuclear enzyme involved in DNA relaxation, is the target of several anticancer drugs. TOPI mutations occur in camptothecin-resistant tumour cell lines. We explored, in the $\mathrm{NCl}$ panel of 60 human tumour cell lines, whether polymorphic variations in the TOPI gene could explain differences in drug sensitivity. The 21 exons of the gene were fully studied as well as five intronic domains that had previously been shown to harbour single nucleotide polymorphisms (SNPS) or mutations. PCR products covering the whole exonic sequences or the relevant intronic domains were subjected to denaturing high-performance liquid chromatography. Nucleotide variations were then determined by sequencing. Discrimination between intronic common and variant homozygous samples was performed using a restriction fragment length polymorphism technique. Only one exonic mutation was detected, at the heterozygous state; it occurs in exon 19 of a colon cancer cell line (HCT-I5) and consists of a G > A transition at position 75, resulting in a Met675lle change. The intronic sequences studied harboured the SNPs expected with allelic frequencies between 20 and 40\%. Three major haplotypes, generating $92 \%$ of the 10 genotypes encountered, were defined as containing none of the intronic SNPs, or three of them, or all of them. No significant relationship was evidenced between Top I expression and the TOP I polymorphisms studied. However, when comparing the cytotoxicity of I 38 drugs as a function of the genotypes, several drug groups, namely Top I inhibitors, antifolates and taxanes, had significantly different $\mathrm{IC}_{50} \mathrm{~s}$ as a function of the distribution of the intronic SNPs of the TOPI gene.

British Journal of Cancer (2006) 95, 906-913. doi:I0.1038/sj.bjc.660336I www.bjcancer.com

Published online 19 September 2006

(c) 2006 Cancer Research UK

Keywords: anticancer drug cytotoxicity; camptothecins; DNA topoisomerase I; gene polymorphisms; $\mathrm{NCl}-60$ panel

Human DNA topoisomerase I (Top1) is a monomeric nuclear protein of $91 \mathrm{kDa}$ (765 amino acids) encoded by a gene located on chromosome $20(20 \mathrm{q} 12-13.2)$. Topoisomerase 1 is the target enzyme of several anticancer drugs used in the clinics (camptothecins) or in development (indolocarbazoles) (Pommier et al, 1999). Topoisomerase 1 is able to relax supercoiled DNA, downstream the replication and transcription machineries, through the formation of transitory single-strand breaks. During the catalytic process, a transesterification occurs, with tyrosine 723 of the active centre forming a covalent bond with a $3^{\prime}$ phosphate group, allowing the nicked DNA strand to rotate about the intact strand, and relieving thus by one turn the torsional constraint. Topoisomerase 1 also catalyses the religation of nicked strand, restoring DNA continuity. Topoisomerase 1-interfering drugs convert the enzyme into a cellular poison by inhibiting the religation step, trapping thus the

\footnotetext{
* Correspondence: Professor J Robert; Laboratoire de Pharmacologie des Agents Anticancéreux, Institut Bergonié, 229 Cours de l'Argonne, 33076, Bordeaux-cedex, France; E-mail: robert@bergonie.org

Received 19 July 2006; revised 18 August 2006; accepted 22 August 2006; published online 19 September 2006
}

enzyme into a stable covalent DNA complex. Cytotoxic lesions are likely to result from the collision between the replication fork and the stabilised cleavable complex, transforming thus a single-strand break into a double-strand break (Wang, 1994). It should be noticed that some agents behave as catalytic inhibitors, by inhibiting the cleavage reaction itself; none of them has been yet developed as an anticancer agent (Pommier et al, 1998).

No functional analysis of the polymorphisms of the TOP 1 gene has been undertaken; such polymorphisms could lead to an alteration of the level of expression and/or the activity of the enzyme, which would explain part of the individual variability of response to Top1 inhibitors. Mutations of the TOP1 gene have been observed in tumour cell lines selected for resistance to camptothecin (Takatani et al, 1997; Pommier et al, 1999; Tsurutani et al, 2002; Woo et al, 2002) or sometimes in clinical specimens (Ohashi et al, 1996), indicating that amino-acid changes could have consequences on cell response to this drug. In addition, a decreased expression of Top1 has been associated to resistance to camptothecin (Sorensen et al, 1995); although the mechanism involved in this decrease has not been identified, it could result from alterations of regulatory sequences in the promoter of the gene. Numerous functional polymorphisms have been identified in 
drug-metabolising enzymes or drug transporters, as well as in drug receptors and targets (see Robert et al, 2005, for review). For instance, a polymorphism located in the $5^{\prime}$ untranslated domain of thymidylate synthase, the target enzyme for fluoropyrimidines, is associated with a change in protein expression and, consequently, in cellular response to the drug (Pullarkat et al, 2001). Therefore, identifying functional polymorphisms in the TOP1 gene could prove of interest for understanding the individual variability of drug effects.

Research and identification of functional polymorphisms in genes involved in drug response and toxicity generally require abundant clinical resources, with numerous patients treated with the drug and fully documented clinical files. This is especially difficult in oncology, because patients are often treated with drug combinations and because the clinical end points are multiple and sometimes difficult to record. Looking for a cellular model able to provide clues and tracks about the functional polymorphisms of the TOP1 gene, we decided to use the National Cancer Institute (NCI) panel of 60 human tumour cell lines. This panel was initially established for high-throughput screening of natural products and synthetic molecules, on the basis of their antiproliferative properties (Monks et al, 1991). In addition, a number of molecular markers and gene expression profiles have been determined in the panel, allowing to establish relationships between chemo-sensitivity or -resistance and the molecular features of the cells (Scherf et al, 2000). The inverse correlation between fluorouracil cytotoxicity and dihydropyrimidine dehydrogenase gene expression has served as a paradigm for such studies. We and others have developed data mining on the NCI database in order to discover relationships between drug activity and cell molecular properties (Robert et al, 2004; Vekris et al, 2004). It should be mentioned that no relationship between TOP1 gene expression and camptothecin cytotoxicity has been detected (Goldwasser et al, 1995).

No analysis of gene polymorphisms has yet been performed on the NCI panel. As it consists of tumour cells, they can present many somatic genetic alterations, distinct from an actual constitutive polymorphism present in the patient who hosted the tumour. We think, however, that the NCI panel could represent a valuable starting point to study the role of gene point variations on anticancer drug activity. The TOP 1 gene covers about $100 \mathrm{~kb}$ and consists of 21 exons; 248 single nucleotide polymorphisms (SNPs) have been referenced in databases (http://www.ncbi.nlm.nih.gov/ SNP/snp_ref.cgi?locusId $=7150$ ), but the frequency of only 49 has been established. One of them only is present in a coding domain (exon 12), with a heterozygosity frequency of 0.043 in an AfricanAmerican population but it was not detected in a Caucasian population (http://www.ncbi.nih.gov/SNP/snp_ss.cgi?subsnp_id = 23535865). In a first step, we explored in totality the 21 exons of the gene and the $5^{\prime}$ untranscribed region by denaturing highperformance chromatography. In a second step, we analysed specifically five intronic SNPs chosen among the 15 that were known to have a frequency higher than 0.25 , localised in introns 2 , $3,6,8$ and 17 , covering about $82 \mathrm{~kb}$. In addition to the study of the NCI panel, we also explored the TOP1 exons of a standard Caucasian population. The relationship between the presence of a given SNP in the TOP1 gene of the NCI panel cell lines and the expression of the TOP 1 gene or the cytotoxicity of 138 standard anticancer drugs was then studied, based on the publicly available NCI databases (http://dtp.nci.nih.gov).

\section{MATERIALS AND METHODS}

\section{Biological samples}

Frozen cell pellets from 59 of the $60 \mathrm{NCI}$ cell lines of the panel were kindly provided by Dr S Holbeck, Cancer Therapeutic Branch, NCI, Bethesda, MD, USA. One cell line, MDA-N, is no longer available in the panel.

Genomic DNAs of a healthy Caucasian French population (53 samples) were kindly provided by the Laboratory of Genetics of Institut Bergonié. All individuals had given written consent for a scientific use of their blood samples.

\section{Molecular biology techniques}

Genomic DNA was extracted from cell pellets using QIAamp ${ }^{\circledR}$ DNA minikit from Qiagen (Courtaboeuf, France). It was quantified by spectrophotometry. DNA electrophoresis was performed on agarose gels in Tris-acetate-EDTA buffer ( $\mathrm{pH}$ 8.0).

Polymerase chain reactions (PCR) were performed on $40 \mathrm{ng}$ genomic DNA, using Platinum ${ }^{\circledR}$ Taq polymerase (Invitrogen, Cergy-Pontoise, France) and a GenAmp PCR system $9700^{\mathbb{R}}$ thermocycler (Applied Biosystems, Courtaboeuf, France). The oligonucleotide primers were determined using the Primer 3 software, from the TOP1 gene sequence (NT_011362). They were designed in order to cover the complete sequences of the exons, the $5^{\prime}$ untranscribed region up to 350 nucleotides upstream exon 1 , and, for introns, the short sequences where a SNP had been localised (see Figure 1). Tables 1 and 2 present the sequences of the primers used for PCR as well as the length of the PCR products.

PCR products were submitted to denaturing high-performance liquid chromatography (dHPLC) in order to identify heterozygous DNA samples in the TOP1 exons of the cell lines of the panel. We used a Wave Nucleic Acid Fragment Analysis System ${ }^{\circledR}$ (Transgenomic, Elancourt, France) with a ion-exchange column and a gradient of acetonitrile in triethyl ammonium acetate buffer as a solvent. In this system, heteroduplexes are eluted more rapidly than homoduplexes, revealing the presence of a SNP on one DNA strand. Homozygous variants cannot be discriminated from homozygous common alleles with this system.

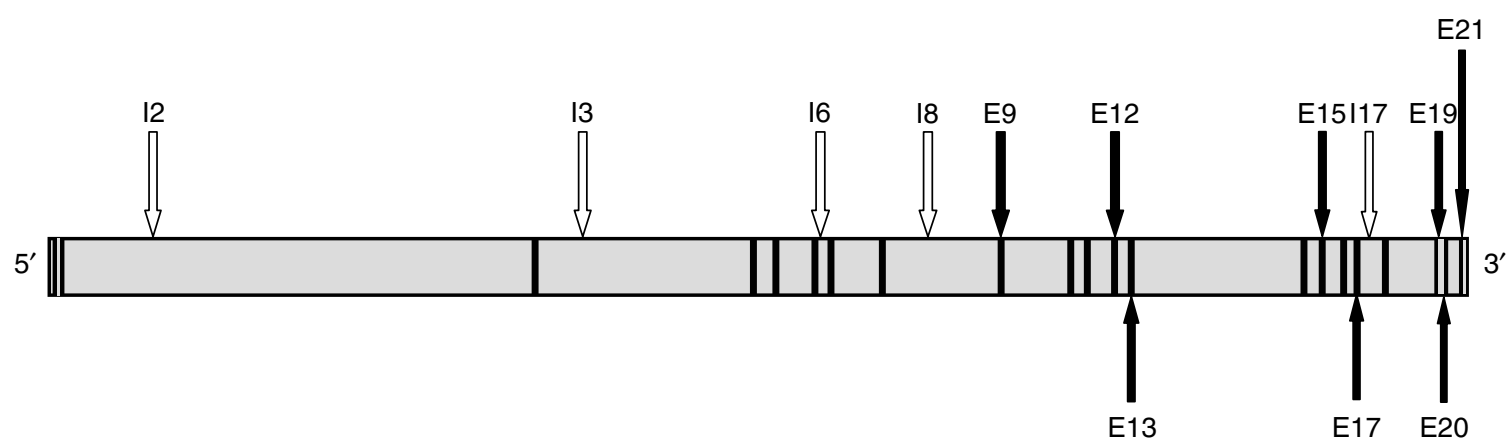

Figure I Genomic structure of the TOPI gene. The exons (E) and introns (I) specifically mentioned in the text are indicated by arrows and they are numbered accordingly. 
Table I Primer sequences for the PCR of the 21 exons of the TOPI gene

\begin{tabular}{|c|c|c|c|c|}
\hline SNP & Localisation $^{\mathbf{a}}$ & Primer sequence & $\begin{array}{l}\text { Exon length } \\
\text { (bp) }\end{array}$ & $\begin{array}{l}\text { Amplicon } \\
\text { length (bp) }\end{array}$ \\
\hline $5^{\prime} \cup T R$ & $\begin{array}{l}\text { G4709344T } \\
\text { rs6072250 }\end{array}$ & $\begin{array}{l}\text { S: GATACCAGCTCTGCCCAAGA } \\
\text { As: AGACTCCAGAAACGGCTGAG }\end{array}$ & - & 656 \\
\hline Exon 2 & & $\begin{array}{l}\text { S: GGCCGCGAAGTTACAGTT } \\
\text { As: ACGCCATGTCTGTCCTCT }\end{array}$ & 25 & 285 \\
\hline Exon 4 & & $\begin{array}{l}\text { S: GGCTAACGCTITGTGACTTA } \\
\text { As: CCTTCCTCCCCTACTAGAAA }\end{array}$ & 124 & 184 \\
\hline Exon 5 & & $\begin{array}{l}\text { S: CCAGGAACTGATGCTACATA } \\
\text { As: TTGGGTTAACTCAGACAACA }\end{array}$ & 56 & 233 \\
\hline Exon 6 & & $\begin{array}{l}\text { S: CACTCTGACCAGCAATTTIT } \\
\text { As: AGTTCAGAGAAATCAGTCCA }\end{array}$ & 96 & 280 \\
\hline Exon 7 & & $\begin{array}{l}\text { S: TGTATTCATGTTCCCCTTC } \\
\text { As: AGCCCCAAAGGACCTAAG }\end{array}$ & 76 & 130 \\
\hline Exon 10 & & $\begin{array}{l}\text { S: TCACTITTGGAACCACTTT } \\
\text { As: ACTTGATTGTITTGCAAGGT }\end{array}$ & 122 & 201 \\
\hline Exon 11 & & $\begin{array}{l}\text { S: TCCCCATTTCTITGACTA } \\
\text { As: ATTCCAGAATTCTCCAGAGG }\end{array}$ & 123 & 184 \\
\hline Exon 12 & $\begin{array}{l}\text { G478I682A (Arg349Arg) } \\
\text { rs6029545 }\end{array}$ & $\begin{array}{l}\text { S: TCAGACTITCCTCTACCTTGA } \\
\text { As: CTIIITGGCCCATAGGAT }\end{array}$ & 188 & 325 \\
\hline Exon 13 & Gly418Lys & $\begin{array}{l}\text { S: TTCACTATCCTCGTGCTCT } \\
\text { As: AGGTTATCAGCACCATGAAC }\end{array}$ & 145 & 223 \\
\hline Exon 14 & & $\begin{array}{l}\text { S: TGCCTGGCTATATTCAAAGT } \\
\text { As: GATGGGAAGATGCTCTCAC }\end{array}$ & 144 & 238 \\
\hline Exon 15 & $\begin{array}{l}\text { G479562IA (Glu5 I7Lys) } \\
\text { rs6I29757 }\end{array}$ & $\begin{array}{l}\text { S: ATGTCTCTTCCATTCATGCT } \\
\text { As: ACCCATGCTTGTTGAATAAT }\end{array}$ & 186 & 288 \\
\hline Exon 16 & & $\begin{array}{l}\text { S: TGCAAGTTTCTTTAAGTTTGG } \\
\text { As: TTCAACATTGTGTGCTTCAT }\end{array}$ & 69 & 181 \\
\hline
\end{tabular}

aThis refers to mutations or SNPs mentioned in databases and that have been especially sought.

Nucleotide sequencing of PCR products was achieved using an ABI 377 sequencer (Perkin Elmer, Courtaboeuf, France) and the ABI PRISM Dye Terminator Cycle Sequencing ${ }^{\circledR}$ kit (Perkin Elmer), which uses the dideoxynucleotide technique of Sanger et al (1977) with four different fluorochromes.

A restriction fragment length polymorphism (RFLP) technique could be set up for four of the five known intronic SNPs, using the same PCR primers as those used for dHPLC. This allowed the rapid identification of homozygous (common and variant) samples for each of the variations, as well as a confirmation for the heterozygous samples. Table 2 lists the restriction enzymes that were used for the digestions. All of them were purchased from Ozyme (Saint-Quentin-en-Yvelines, France). For the variation in intron 17, for which no restriction site could be modified by the variation, common and variant homozygous samples were discriminated by dHPLC of a mixture of a known common homozygous sample with the unknown sample.

\section{Relationships between gene polymorphisms and drug cytotoxicity}

After identification of the genotypes of each cell line, the $\mathrm{IC}_{50}$ values of 138 core drugs vis-à-vis the 59 cell lines, expressed as $-\log _{10}\left(\mathrm{IC}_{50}\right)$, were extracted from the NCI database; mean values were calculated for common homozygous, variant homozygous and heterozygous cell lines for each of the variations encountered, and were compared by analysis of variance. Drugs were then grouped as a function of their known mechanism of action into eight categories (see Scherf et al (2000) for details): alkylating or platinating agents acting on $\mathrm{N}^{7}$ of guanine; other alkylating agents, acting on $\mathrm{N}^{2}$ and $\mathrm{O}^{6}$ of guanine; antimetabolites; antifolates; topoisomerase I inhibitors; topoisomerase II inhibitors; spindle poisons, which could be subdivided into vinca-alkaloid-type and taxane-type mechanisms of action. Only 10 drugs out of 138 remained unclassified because of disagreement about their precise 
Table 2 Primer sequences for the PCR of the five intronic regions known as harbouring frequent SNPs

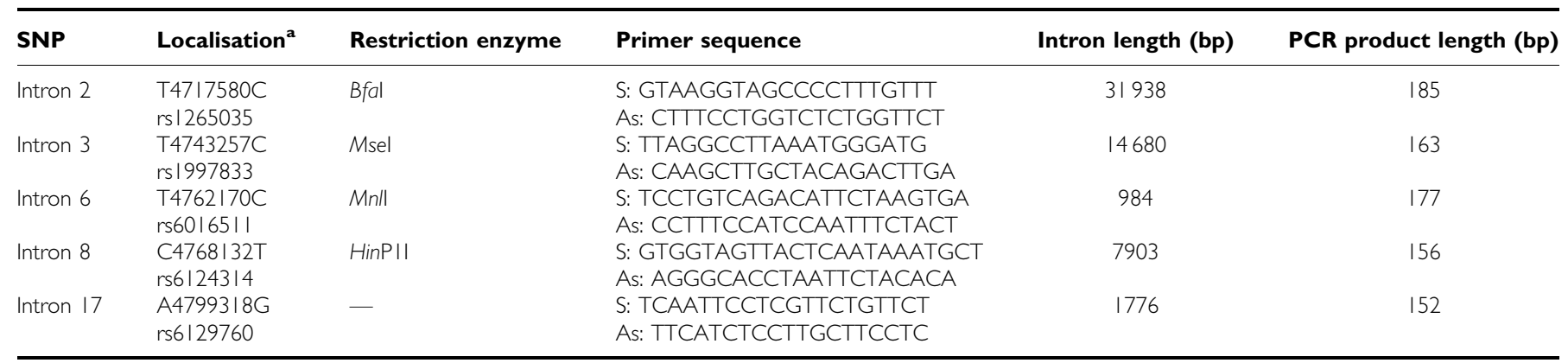

${ }^{\text {aT }}$ This refers to the variations mentioned in databases.

mechanism of action. In order to compare drug groups, the individual $\mathrm{IC}_{50}$ values were normalised by subtracting individual values from the mean value of the 60 -cell line panel. Using a univariate general linear model, we compared the variance of the $\mathrm{IC}_{50} \mathrm{~s}$ for each genotype and we calculated the significance of the differences in the mean $\mathrm{IC}_{50} \mathrm{~s}$ of each drug group as a function of the genotype of the cell lines. This model allows to take into account the unbalanced size of the groups. Due to the number of tests performed, we considered as significant only the $P$-values lower than $2.5 \times 10^{-4}$ (Bonferroni correction). All analyses were performed with the SPSS software (version 12.0).

\section{RESULTS}

\section{Research of exonic SNPs}

We studied by dHPLC the PCR products originating from the 21 exons explored, including the intron-exon junctions, and from the $5^{\prime}$ untranscribed region up to 350 nucleotides before exon 1, using the primers indicated in Table 1 . The presence of heteroduplexes was detected in only four PCR products over more than 2000 dHPLC runs that have been performed: in exon 13 of the IGROV1 cell line (ovarian cancer), in exon 17 of the MOLT-4 (leukaemia) and KM-12 (colon cancer) cell lines, and in exon 19 of the HCT-15 line (colon cancer). We explored five exons in the control population (exons 9, 12, 15, 19 and 21) that were selected because they contained the variations encountered in cell lines selected with camptothecin. No heteroduplex was detected in any of these five exons.

After sequencing, it appeared that three of the four variations detected in the cell lines of the NCI panel were indeed intronic, at a short distance of the exon-intron junctions, but not involving the splice site. The only true exonic variation observed was the one located in exon 19 of the HCT-15 cell line; it consists of a G>A transition at position 75 of the exon, resulting in a met $>$ ile aminoacid change at position 675 of the protein.

Because of the very low frequency of the heterozygous DNAs, we found it unlikely to expect the presence of corresponding homozygous variants in either the control population or the NCI panel and no systematic sequencing of the PCR products was undertaken.

\section{Research of intronic SNPs}

We first studied by dHPLC the PCR products originating from the five introns explored, at the sites where a SNP had been mentioned in databases with a frequency $>0.25$, using the primers indicated in Table 2. There were numerous heterozygous samples in the NCI panel. We verified, by sequencing 10 randomly selected samples for each intron, that each variation observed was the one expected from databases. We then set up RFLP techniques for the rapid identification of homozygous (common and variant) samples for each of the variations, as well as a confirmation for the heterozygous samples. Table 3 presents the distribution of the intronic variations among the 59 cell lines of the panel. The frequency of the variations detected was between 20 and $40 \%$.

It clearly appeared that there was a strong linkage disequilibrium between the intronic variations studied. A total of 10 different genotypes were identified and, from these data, it was possible to identify three major haplotypes and four minor haplotypes. A major haplotype $(60 \%)$ was characterised by the absence of all the intronic variations studied, the second one (16\%) by the presence of the variations in introns 3, 6 and 17, and the third one $(20 \%)$ by the presence of all the intronic variations studied. We propose to name these haplotypes A, B and C, respectively. The minor haplotypes were each present in only one cell line and contained $1-4$ of the intronic variations studied. The combinations of the three major haplotypes generated $92 \%$ of all diplotypes and only four cell lines contained another haplotype.

\section{Relationships between gene polymorphisms and drug cytotoxicity}

The HTC-15 cell line (colon cancer) was the only one to harbour a non-synonymous SNP, located in exon 19 . The $-\log \left(\mathrm{IC}_{50}\right)$ of camptothecin in this cell line was 6.82 , as mentioned in the NCI database, to be compared with the mean value $( \pm$ s.d.) of camptothecin $-\log \left(\mathrm{IC}_{50}\right)$ in the 60 cell lines of the panel $(7.38 \pm 0.55)$. This corresponds to a 3.6 -fold resistance of the HCT-15 cell line as compared to the average cell line. Similar findings were obtained with the other topoisomerase I inhibitors of the camptothecin family (topotecan, $\mathrm{SN}-38$ ). The $-\log \left(\mathrm{IC}_{50}\right)$ of rebeccamycin, the indolocarbazole lead compound tested against the NCI panel, is 6.40 in the HCT-15 cell line, which is among the five least sensitive cell lines of the whole panel to this agent (mean value for the panel: $6.70 \pm 0.26$ ). It is not possible, however, to assign a causal relationship between this relative low sensitivity and exon 19 polymorphism, because the HTC-15 line appears as globally chemoresistant to most anticancer drugs (Scherf et al, 2000).

We compared the mean $\mathrm{IC}_{50} \mathrm{~s}$ of 138 core drugs, extracted from the NCI database, in the three genetic status (wild-type homozygous, heterozygous, variant homozygous) of each of the intronic variation studied. Because of the small number of cell lines (3) exhibiting intron 2 or intron 8 variations at the homozygous state, we excluded them from the comparative study because of the possibility of bias. Comparison was also made as a function of the presence or absence of each of the three main haplotypes in the genotype of the cell lines. When considered individually, none of the 138 drugs had $\mathrm{IC}_{50}$ values significantly different according to the genotype, after Bonferroni adjustment. We then constituted drug groups on the basis of their mechanism of action (Scherf et al, 2000), and compared the normalised mean $\mathrm{IC}_{50}$ values of 
Table 3 Distribution of the intronic SNPs among the cell lines of the $\mathrm{NCl}-60$ panel

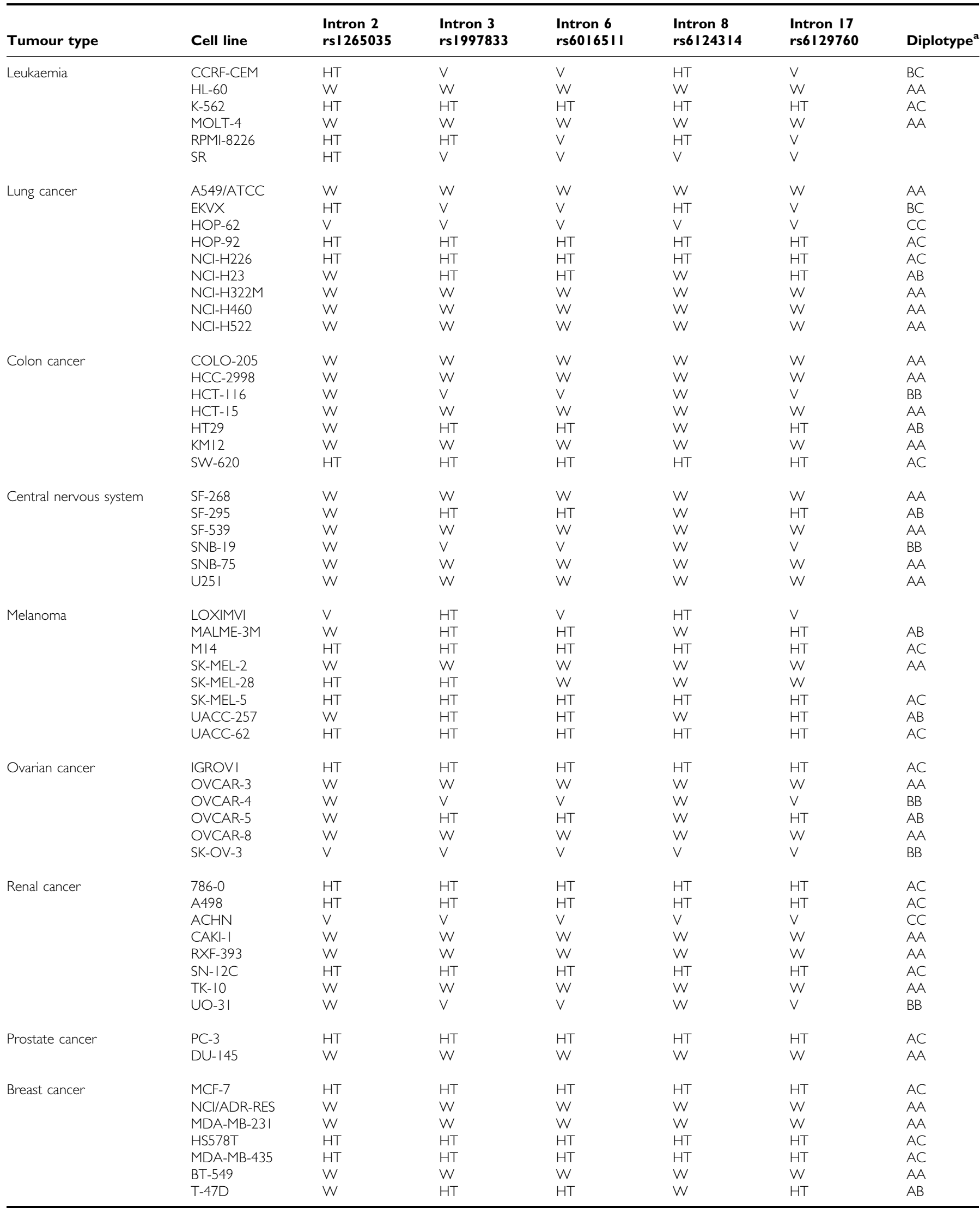

${ }^{\mathrm{a}}$ Four diplotypes could not be ascertained due to the presence of rare haplotypes. 
each drug group in the different genotypes. In order to avoid to take into account apparently significant relationships between drug sensitivity and polymorphic variations, which would result from chance only, we exclusively considered as relevant the differences in mean $\mathrm{IC}_{50}$ values of at least $50 \%\left(\mathrm{IC}_{50}\right.$ ratios $>1.5$ or $<0.67$ ) (biological significance) and giving a $P$-value $<10^{-4}$ (statistical significance). The presence of variations in introns 2 and 8 (which are concomitant in 21 cell lines) appeared associated to a higher sensitivity to antifolates and taxanes (Table 4), whereas the presence of variations in introns 3, 6 and 17 (which are concomitant in 33 cell lines) was associated to sensitivity to topoisomerase I inhibitors and to resistance to taxanes.

When haplotypes were considered, it appeared that the presence of at least one allele $\mathrm{A}$ in the genotype (47 cell lines) was significantly associated to resistance to Top1 inhibitors and to sensitivity to taxanes; the presence of at least one allele B (14 cell lines) was significantly associated to sensitivity to taxanes and antifolates; and the presence of at least one allele C ( 22 cell lines) was associated to sensitivity to Top 1 inhibitors, antifolates and taxanes (Figure 2).

We also compared the Top 1 expression data, as extracted from the NCI database, to the genetic status of the intronic variations and of haplotype distribution. Among the various microarray data in the NCI database (http://dtp.nci.nih.gov), those performed independently by two groups with the U95A and the U133A Affymetrix chips appeared as the more reliable and they were used for comparisons with drug cytotoxicity and with TOP1 genotypes. There was no significant correlation between TOP1 gene expres- sion and the cytotoxicity of Top1 inhibitors vis-à-vis the NCI-60 panel, and we found no correlations either between TOP1 gene expression and the gene polymorphisms. As the TOP1 gene copy number could be a confounding factor for establishing relationships between gene polymorphisms and gene expression, we corrected the expression data in the NCI database by dividing the expression levels by the number of chromosome $20 \mathrm{q}$ arms in the cell line, as extracted from the karyotype description (http:// www.ncbi.nlm.nih.gov/sky/skyweb/cgi), but we evidenced not better relationships.

\section{DISCUSSION}

This is the first time, to our knowledge, that the genomic variations of Top1 were studied in a variety of tumour and normal samples. Topoisomerase 1 appears in this study as a highly conserved protein, with exceptional variations in the coding sequence. This is probably in relation to the crucial importance of this enzyme activity in cell life. Only one exonic variation was found in 59 different tumour cell lines and 53 DNA samples of healthy individuals. This variation is able to determine an amino-acid change at position 675 of the protein, in a domain which is not far from the catalytic tyrosine (amino acid 723) but in a linker region where no drug-induced mutation able to confer drug resistance has been identified (Ohashi et al, 1996; Takatani et al, 1997; Pommier et al, 1999; Tsurutani et al, 2002; Woo et al, 2002). For this reason, we have not tried to detect the variant protein in the

Table 4 Relationships between intronic SNPs and drug sensitivity in the cell lines of the NCl-60 panel

\begin{tabular}{|c|c|c|c|c|c|c|c|}
\hline & & \multicolumn{2}{|c|}{ Top I inhibitors (18) } & \multicolumn{2}{|c|}{ Antifolates (II) } & \multicolumn{2}{|c|}{ Taxanes (13) } \\
\hline & & $I C_{50}$ ratio & $P$-value & $I C_{50}$ ratio & $P$-value & $I C_{50}$ ratio & $P$-value \\
\hline Intron $8^{\mathrm{a}}$ & HT vs W & 1.25 & $6.8 \times 10^{-5}$ & 2.69 & $5.7 \times 10^{-8}$ & 2.12 & $1.5 \times 10^{-12}$ \\
\hline \multirow[t]{2}{*}{ Intron 3} & V vs W & 1.85 & $5.7 \times 10^{-8}$ & 1.39 & 0.86 & 0.46 & $2.8 \times 10^{-9}$ \\
\hline & V vs HT & 1.83 & $1.1 \times 10^{-7}$ & 0.79 & 0.037 & 0.34 & $2.1 \times 10^{-11}$ \\
\hline Introns 6 and $17^{b}$ & V vs W & 2.01 & $1.0 \times 10^{-8}$ & 2.21 & 0.064 & 0.69 & $2.3 \times 10^{-5}$ \\
\hline Allele B & Abs. vs Pres. & 1.16 & 0.006 & 2.72 & $8.1 \times 10^{-7}$ & 2.21 & $2.6 \times 10^{-12}$ \\
\hline Allele C & Abs. vs Pres. & 0.70 & $5.0 \times 10^{-10}$ & 0.39 & $4.4 \times 10^{-8}$ & 0.58 & $1.0 \times 10^{-10}$ \\
\hline
\end{tabular}

Abbreviations: Abs., absent; HT, heterozygous; Pres., present; $\mathrm{V}$, variant; $\mathrm{W}$ : wild-type. ${ }^{\mathrm{a}}$ Due to the small number (three) of homozygous variants for these variations, comparisons of their $\mathrm{IC}_{50}$ s with wild-type and heterozygous samples were not made. ${ }^{\mathrm{b}}$ All cell lines presented the same variations of introns 6 and 17.
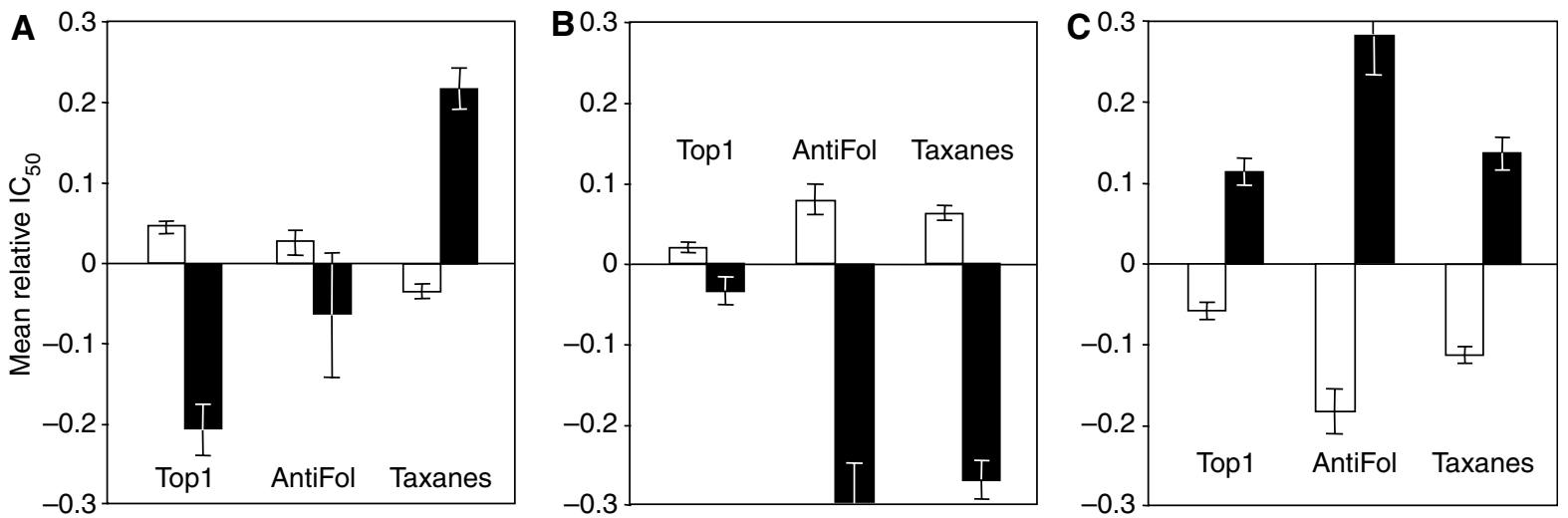

Figure 2 Schematic representation of the association between the presence or absence of a given allele in the genotype of the cell lines of the $\mathrm{NCl}-60$ panel and the cytotoxicity of Top I inhibitors, antifolates and taxanes. The mean $I C_{50}$ s of drug classes towards the 60 cell lines, expressed as $-\log \left(I C_{50}\right)$, were equalled to zero, the cytotoxicities higher than the mean were given a positive sign and the cytotoxicities lower than the mean a negative sign. White columns: absence of allele A, B or C in the genotype; black columns: presence of allele A, B or C in the genotype. 
corresponding cell line and we do not know whether it is expressed and whether it shares the same catalytic properties as the common enzyme. It is also difficult to know whether this variation is a polymorphism that can be encountered in normal subjects with low frequency or a tumour somatic mutation generated during the process of oncogenesis.

This is also the first report on the haplotype distribution of TOP1 in a panel of human tumours. The most frequent intronic variations described in the databases have been found at the expected location and with the expected frequency. As we have explored, from intron 2 to intron 17 , about $82 \%$ of the length of the TOP1 gene, we have obtained a global insight of the haplotype distribution. Only three different haplotypes were present in 55 cell lines out of 59, the four remaining cell lines harbouring different haplotypes, in combination with the $\mathrm{A}$ and $\mathrm{C}$ haplotypes. Haplotypes were distributed randomly among the various cell lines, with no specificity for the tissue of origin of the tumour cell lines, suggesting that they reflect the constitutive distribution of the individuals from whom the tumour was isolated and grown in culture. There was no relationship between haplotype distribution and the cytogenetic status of the cell lines, which was studied in detail by Roschke et al (2003) and is freely available on the NCBI site (http://www.ncbi.nlm.nih.gov/sky/skyweb/cgi): the three main haplotypes were present in cells which were diploid, polyploid or aneuploid for chromosome 20, and so were also the rare haplotypes.

The intronic SNPs of TOP1 have been determined by the Hapmap consortium in a normal Caucasian population of 91 subjects from the Centre d'Étude du Polymorphisme Humain (CEPH) (http://www.hapmap.org), 84 of whom could be assigned as presenting a combination of the three main haplotypes $\mathrm{A}, \mathrm{B}$ and C. The frequencies of alleles A, B and C were similar in this population and in the NCI panel. However, when considering the distributions of $\mathrm{A}, \mathrm{B}$ and $\mathrm{C}$ haplotypes in terms of common homozygous, heterozygous and variant homozygous genotypes, it appeared that the number of $\mathrm{AB}$ heterozygous samples was slightly lower than expected in the NCI panel from the HardyWeinberg distribution $(P=0.073)$. This means that a loss of heterozygosity may have occurred during the process of oncogenesis for allele $\mathrm{B}$, but not for allele $\mathrm{C}$. As a consequence, several cell lines considered as homozygous for allele $\mathrm{B}$ must rather be hemizygous for at least a part of chromosome 20. Loss of heterozygosity is also evident from the comparisons that can be done on cell lines which have been recently shown to originate from the same individual (Holbeck, personal communication, August 8, 2005; see Garraway et al, 2005): NCI/ADR-RES and OVCAR-8, M14 and MDA-MB-231 and U251 and SNB-19. For two of these pairs, the genotypes we identified were different, which can only be explained by loss of heterozygosity having occurred in one of the cell lines.

The relationships between drug cytotoxicity and the polymorphism of TOP1 cannot be explained by a simple effect on TOP1 gene expression or enzyme intrinsic activity, as no significant relationship could be evidenced between the polymorphisms and the gene expression data, even after correction by the TOP 1 gene copy number. The gene expression database of the NCI may not appear very robust, with 10 microarray data sets obtained with various distinct oligonucleotides, and no data set obtained with a reference technique such as quantitative RT-PCR. We only used the microarray data obtained with the U95A and the U133A Affymetrix chips, which were provided by two independent groups working on distinct RNA extracts and gave strongly correlated results. There appears to be a lower reliability of data from the U95B-E and U133B chips, which has been observed with many other genes and may reflect incorrect mapping of the gene to that Affymetrix feature. Even if we missed a correlation between TOP1 polymorphisms and Top1 expression, the mechanism by which the corresponding haplotype would influence Top1 expression remains elusive. Furthermore, the relationships between cell sensitivity to antifolates and taxanes and the haplotype distribution of TOP1 genotypes cannot be explained at this point from a pharmacological point of view.

It must be kept in mind that polymorphisms may only be the reflect of unidentified variations, occurring at a distance from the SNP studied, and playing the actual mechanistic effect on the cellular properties observed. Several genes involved in cell proliferation and oncogenesis are present in the vicinity of the TOP1 gene and belong to the same haplotypic block: they could well be the true responsible for the association observed between TOP1 polymorphisms and drug cytotoxicity. This is especially the case for the gene $Z H X 3$, which encodes a zinc-finger protein involved in the repression of transcription. There is a common non-synonymous polymorphism on this gene (Ser310Asn), with a rare allele frequency of 0.208 in Caucasians, which is significantly associated with the variant haplotypes of the TOP1 gene, and whose functionality is not known and should be explored (http:// www.ncbi.nlm.nih.gov/SNP/snp_ref.cgi?rs = 17265513).

Nevertheless, even if the mechanism relating TOP1 polymorphisms to drug cytotoxicity remains unidentified, it might be of interest to identify such associations, that may be used as predictive factors of drug activity, once the in vitro observation has been transferred to the clinical setting. We are planning retrospective studies on DNA samples from cancer patients who have been treated, for instance, with combinations of antifolates (such as raltitrexed) and Top1 inhibitors (such as irinotecan) in order to validate our observations.

\section{ACKNOWLEDGEMENTS}

This work was supported by grants from the Association pour la Recherche sur le Cancer. It is part of the Master 2 research project of FM. We thank Mrs B Gastaldello, Laboratory of Genetics, Institut Bergonié, Bordeaux, for monitoring the dHPLC experiments. We are grateful to Dr S Holbeck, National Cancer Institute, Bethesda, for making available the NCI-60 panel for this study.

\section{REFERENCES}

Garraway LA, Widlund HR, Rubin MA, Getz G, Berger AJ, Ramaswamy S, Beroukhim R, Milner DA, Granter SR, Du J, Lee C, Wagner SN, Li C, Golub TR, Rimm DL, Meyerson ML, Fisher DE, Sellers WR (2005) Integrative genomic analyses identify MITF as a lineage survival oncogene amplified in malignant melanoma. Nature 436: $117-122$

Goldwasser F, Bae I, Valenti M, Torres K, Pommier Y (1995) Topoisomerase I-related parameters and camptothecin activity in the colon carcinoma cell lines from the National Cancer Institute anticancer screen. Cancer Res 55: 2116-2121
Monks A, Scudiero D, Skehan P, Shoemaker R, Paull K, Vistica D, Hose C, Langley J, Cronise P, Wolff AV, Goodrich MG, Campbell H, Mayo J, Boyd M (1991) Feasibility of a high flux anticancer drug screen using a diverse panel of cultured human tumor cell lines. J Natl Cancer Inst 83: 757-766

Ohashi N, Fujiwara Y, Yamaoka N, Katoh O, Satow Y, Yamakido M (1996) No alteration in DNA topoisomerase I gene related to CPT-11 resistance in human lung cancer. Jpn J Cancer Res 87: 1280-1287

Pommier Y, Pourquier P, Fan Y, Strumberg D (1998) Mechanism of action of eukaryotic DNA topoisomerase I and drugs targeted to the enzyme. Biochim Biophys Acta 1400: 83-105 
Pommier Y, Pourquier P, Urasaki Y, Wu J, Laco GS (1999) Topoisomerase I inhibitors: selectivity and cellular resistance. Drug Resist Updat 2: $307-318$

Pullarkat ST, Stoehlmacher J, Ghaderi V, Xiong YP, Ingles SA, Sherrod A, Warren R, Tsao-Wei D, Groshen S, Lenz HJ (2001) Thymidylate synthase gene polymorphism determines response and toxicity of 5-FU chemotherapy. Pharmacogenomics J 1: 65-70

Robert J, Le Morvan V, Smith D, Pourquier P, Bonnet J (2005) Predicting drug response and toxicity based on gene polymorphisms. Crit Rev Oncol Hematol 54: 171 - 196

Robert J, Vekris A, Pourquier P, Bonnet J (2004) Predicting drug response based on gene expression. Crit Rev Oncol Hematol 51: 205-227

Roschke AV, Tonon G, Gehlhaus KS, McTyre N, Bussey KJ, Lababidi S, Scudiero DA, Weinstein JN, Kirsch IR (2003) Karyotypic complexity of the NCI-60 drug-screening panel. Cancer Res 63: 8634-8647

Sanger F, Nicklen S, Coulson AR (1977) DNA sequencing with chainterminating inhibitors. Proc Natl Acad Sci USA 74: 5463-5467

Scherf U, Ross DT, Waltham M, Smith LH, Lee JK, Tanabe L, Kohn KW, Reinhold WC, Myers TG, Andrews DT, Scudiero DA, Eisen MB, Sausville EA, Pommier Y, Botstein D, Brown PO, Weinstein JN (2000) A gene expression database for the molecular pharmacology of cancer. Nat Genet 24: $236-244$
Sorensen M, Sehested M, Jensen PB (1995) Characterisation of a human small-cell lung cancer cell line resistant to the DNA topoisomerase Idirected drug topotecan. Br J Cancer 72: 399-404

Takatani H, Oka M, Fukuda M, Narasaki F, Nakano R, Ikeda K, Terashi K, Kinoshita A, Soda H, Kanda T, Schneider E, Kohno S (1997) Gene mutation analysis and quantitation of DNA topoisomerase $\mathrm{I}$ in previously untreated non-small cell lung carcinomas. Jpn J Cancer Res 88: $160-165$

Tsurutani J, Nitta T, Hirashima T, Komiya T, Uejima H, Tada H, Syunichi N, Tohda A, Fukuoka M, Nakagawa K (2002) Point mutations in the topoisomerase I gene in patients with non-small cell lung cancer treated with irinotecan. Lung Cancer 35: 299-304

Vekris A, Meynard D, Haaz MC, Bayssas M, Bonnet J, Robert J (2004) Determinants of the clinical activity of platinum compounds: the contribution of in silico research. Cancer Res 64: 356-362

Wang JC (1994) An introduction to DNA supercoiling and DNA topoisomerase - catalyzed linking number changes of supercoiled DNA. Adv Pharmacol 29B: $257-270$

Woo MH, Vance JR, Marcos AR, Bailly C, Bjornsti MA (2002) Active site mutations in DNA topoisomerase I distinguish the cytotoxic activities of camptothecin and the indolocarbazole, rebeccamycin. I Biol Chem 277: $3813-3822$ 